\title{
ANALISIS IMPLEMENTASI PERAN SUMBERDAYA MANUSIA SEBAGAI MITRA STRATEGIK, AHLI ADMINISTRATIF, EMPLOYEE CHAMPION, DAN AGEN PERUBAHAN: STUDI PADA TOP COMPANIES DI INDONESIA
}

\author{
Siti Fatimah Nurhayati*)
}

\begin{abstract}
The change and increasingly complex business environment has forced many companies to make radical organizational transformation. Facing with this new challenge, the organization should develop their competitive advantage on the basis of organizational capabilities and the execution of new roles of human resource. This research analyzes the execution of the human resource roles at top companies in Indonesia. The result shows that generally top companies in Indonesia have executed four types of human resource roles (strategic partner, administrative expert, employee champion and the change agent role), nevertheless the execution pattern of human resource roles are different. The execution of one role will support the execution of other role.
\end{abstract}

Keywords: The change and increasingly complex business environment, radical organizational transformation, the new roles of human resource.

\section{PENDAHULUAN}

Sumberdaya manusia kurang diperhatikan orang sebab hasil investasi di bidang sumberdaya manusia sukar dikuantitatifkan, sulit dilihat dan bersifat jangka panjang (Ulrich, 1998: 124). Perhatian mereka lebih ditekankan pada keunggulan organisasional yang dicapai melalui berbagai upaya. Instrumeninstrumen manajemen yang dianggap ampuh merealisasi kebutuhan tersebut adalah dengan penataan ulang proses bisnis secara radikal melalui perubahan struktural maupun kultural, sehingga muncul istilah-istilah seperti benchmarking, core competence, TQM, kaizen, reengineering, rightizing, downsizing, dan lain-lain. Guna mewujudkan ini semua, diperlukan dukungan fungsi sumberdaya manusia untuk implementasinya.

Memperhatikan semua ini, apa yang harus dilakukan bidang sumberdaya manusia? Jawabnya adalah menciptakan suatu peran sumberdaya manusia yang benar-benar baru, dan agenda untuk bidang yang tidak berfokus pada aktifitas sumberdaya manusia tradisional. Manusia tidak boleh didefinisikan dengan apa yang ia lakukan atau kerjakan, melainkan dengan apa yang ia sampaikan dan hasilkan dalam menambah nilai organisasi terhadap pelanggan, baik pelanggan internal maupun eksternal.

Kebutuhan pengembangan kapabilitas organisasi mengarah pada peran baru sumberdaya manusia sebagai sumber kompetitif. Kriteria peran sumberdaya manusia ini berbeda-beda menurut fokus, aktifitas, waktu,

*) Staf Pengajar Fakultas Ekonomi Universitas Muhammadiyah Surakarta 
metafora dan penciptaan nilai. Tabel 1 menunjukkan peran baru sumberdaya manusia menurut beberapa ahli.

Tabel 1

Berbagai Peran Baru Sumberdaya Manusia

\begin{tabular}{|l|l|}
\hline Nama Ahli & Peran Baru Sumberdaya Manusia \\
\hline French (1986) & $\begin{array}{l}\text { Peran diagnostik, fasilitator-katalisator, konsultan dan sebagai } \\
\text { evaluator. }\end{array}$ \\
\hline $\begin{array}{l}\text { Schuler and Jackson } \\
\text { (1987) }\end{array}$ & $\begin{array}{l}\text { Berperan di bidang perencanaan, staffing, penilaian, kompensasi } \\
\text { serta pelatihan dan pengembangan. }\end{array}$ \\
\hline Schuler (1990) & $\begin{array}{l}\text { Oknum bisnis, pembentuk perubahan, konsultan organisasi, } \\
\text { formulator dan implementor strategi, manajer yang berbakat, } \\
\text { pengontrol biaya dan manajer aset. }\end{array}$ \\
\hline Wiley (1992) & $\begin{array}{l}\text { Berperan dalam proses strategik (sebagi konsultan, penilai, } \\
\text { pendiagnosa, agen perubahan, katalisator. Mitra bisnis dan } \\
\text { manajer biaya), aspek legal (sebagi auditor, konsultan, pemberi } \\
\text { atau provider,dan pendamai), aspek operasional (sebagi } \\
\text { peredam permasalahan, agen perubahan, penasehat karyawan, } \\
\text { fasilitator, formulator dan konsultan kebijakan). }\end{array}$ \\
\hline Walker (dalam Ferris, & $\begin{array}{l}\text { Peran pendukung, pemberi service, konsultan dan } \\
\text { kepemimpinan. }\end{array}$ \\
\hline Becker dan Gerhart(1996) & Sebagai pencipta nilai sebagai salah satu keunggulan kompetitif. \\
\hline Conner dan Ulrich (1996) & $\begin{array}{l}\text { Mitra stategik, ahli administratif, pejuang pekerja atau employee } \\
\text { champion dan agen perubahan }\end{array}$ \\
\hline
\end{tabular}

Sumber: Gabungan dari berbagai artikel

Dengan model banyak peran dari sumberdaya manusia akan membantu dalam menilai seluruh kualitas layanan dan jasa sumberdaya manusia. Selain itu, alokasi nilai diantara berbagai peran sumberdaya manusia menunjukkan persepsi saat ini tentang fungsi sumberdaya manusia, mengidentifikasi bidang-bidang sumberdaya manusia yang tumbuh lebih kuat atau lebih lemah, serta untuk mengevaluasi kinerja sumberdaya manusia saat ini. Peran baru sumberdaya manusia akan lebih banyak memberikan nilai tambah bagi organisasi agar lebih efektif dan kompetitif melalui penurunan biaya, berorientasi pada pelanggan, meningkatnya produktifitas serta komitmen pekerja, dan lain-lain (Fryzel \& Wang, 1994).

Penelitian ini merupakan replikasi penelitian Conner dan Ulrich (1996) yang menyatakan bahwa ada pergeseran paradigma peran sumberdaya manusia tradisional ke peran baru sumberdaya manusia, yang disebabkan oleh transformasi manajemen sebagai respon akan perubahan lingkungan. Bertolak dari hal tersebut, perlu untuk menengok "apa yang terjadi dengan top companies di Indonesia ?" 


\section{PERUMUSAN MASALAH}

Pada masa mendatang, organisasi dituntut untuk mampu mengantisipasi berbagai bentuk perubahan lingkungan dan secara proaktif menyusun berbagai perubahan yang diperlukan. Tabel 2 mengidentifikasi beberapa kecenderungan yang membantu memajukan kualitas hidup di tempat kerja modern.

Tabel 2

Kecenderungan Sifat Perubahan di Tempat Kerja

\begin{tabular}{|l|l|l|}
\hline \multicolumn{1}{|c|}{ Isu } & \multicolumn{1}{|c|}{ Lama } & \multicolumn{1}{c|}{ Baru } \\
\hline Struktur organisasi & Banyak tingkatan (vertikal) & Sedikit tingkatan (horisontal) \\
\hline Wewenang & $\begin{array}{l}\text { Tersentralisir ke manajemen } \\
\text { puncak }\end{array}$ & $\begin{array}{l}\text { Tersentralisir dengan } \\
\text { empowerment pada setiap } \\
\text { tingkatan }\end{array}$ \\
\hline Desain pekerjaan & $\begin{array}{l}\text { Sederhana dan sempit, } \\
\text { manajer "berpikir" karyawan } \\
\text { "melaksanakan" }\end{array}$ & $\begin{array}{l}\text { Banyak keahlian dan luas, } \\
\text { karyawan "berpikir" melaksanakan }\end{array}$ \\
\hline Kelompok pekerja & $\begin{array}{l}\text { Penting namun hanya sebagai } \\
\text { unit administrasi yang resmi }\end{array}$ & $\begin{array}{l}\text { Tim dan sisten sosio teknik } \\
\text { ditekankan }\end{array}$ \\
\hline Kompensasi & $\begin{array}{l}\text { Gaji berdasarkan golongan } \\
\text { pekerjaan dan kinerja individu }\end{array}$ & $\begin{array}{l}\text { Gaji berdasarkan ketrampilan dan } \\
\text { kinerja individu dan kelompok }\end{array}$ \\
\hline Pelatihan & $\begin{array}{l}\text { Karyawan mudah diganti, } \\
\text { pelathan hanya terbatas pada } \\
\text { satu pekerjaan }\end{array}$ & $\begin{array}{l}\text { Karyawan sangat dihargai, } \\
\text { didorong untuk melakukan } \\
\text { pembelajaran }\end{array}$ \\
\hline Span of control & Sempit (hirarkis) & Luas (flat) \\
\hline Jumlah staff & Banyak (gemuk) & Sedikit (ramping) \\
\hline Rantai komando & Panjang & Pendek \\
\hline Fokus pada & Produk & Pelanggan \\
\hline Keterlibatan Karyawan & Rendah & Tinggi \\
\hline Sumb: Scheman & \\
\hline
\end{tabular}

Sumber: Schermerhorn (1996).

Berbagai tantangan bisnis yang semakin bertambah kompleks, mengharuskan perusahaan untuk melakukan transformasi radikal di bidang manajemen. Dalan hal ini keunggulan perusahaan ditentukan oleh kapabilitas organisasional. Disini telah jelas bahwa sumberdaya manusia mempunyai peran yang penting. Menurut Ulrich (1997), ada empat peran sumberdaya manusia, yaitu (1) mitra strategik, (2) ahli administratif, (3) pejuang pekerja, dan (4) agen perubahan.

Pertanyaannya sekarang adalah "Apakah top companies di Indonesia telah menerapkan empat peran sumberdaya manusia tersebut?" Hal ini penting mengingat bahwa agar dapat survive, maka organisasi harus bertindak proaktif.

Dalam penelitian ini diberikan perumusan masalah sebagai berikut: Apakah ada perbedaan tingkat pelaksanaan peran mitra strategik, ahli administratif, pejuang pekarja, dan agen perubahan pada top companies di 
Indonesia? Bagaimana pola pelaksanaan peran mitra strategik, ahli administratif, pejuang pekerja, dan agen perubahan antar perusahaan-perusahaan yang tergolong dalam top companies di Indonesia? Apakah bersifat homogen atau heterogen? Adakah saling hubungan antara peran mitra stategik, ahli administratif, pejuang pekerja, dan agen perubahan pada top companies di Indonesia?

Adapun tujuan penelitian yang ingin dicapai dalam penelitian ini adalah: Membandingkan peran mana yang paling banyak dipraktikkan di antara peran mitra stategik, ahli administratif, pejuang pekerja dan agen perubahan pada top companies di Indonesia, menganalisis kehomogenan dan keheterogenan pelaksanaan peran mitra strategik, ahli administratif, pejuang pekerja, dan agen perubahan antar perusahaan-perusahaan yang tergolong dalan top companies di Indonesia dan menganalisis hubungan antar berbagai peran (mitra stategik, ahli administratif, pejuang pekerja, dan agen perubahan) pada top companies di Indonesia.

\section{LANDASAN TEORI DAN HIPOTESIS}

Perkembangan fungsi sumberdaya manusia mengikuti sejarah bisnis di United States. Sejarah perkembangan fungsi sumberdaya manusia dapat dilihat pada tabel 3 .

Tabel 3

Sejarah Perkembangan Fungsi Sumberdaya Manusia

\begin{tabular}{|l|l|}
\hline \multicolumn{1}{|c|}{ Periode dan Tokoh } & \multicolumn{1}{|c|}{ Fungsi Sumberdaya Mannusia } \\
\hline 1950-an: Miles dan Snow & $\begin{array}{l}\text { Rekrutmen, seleksi, record keeping, training, time and motion } \\
\text { studies, kesejahteraan dan hubungan serikat kerja }\end{array}$ \\
\hline 1960-1970: Friedman & $\begin{array}{l}\text { Hubungna tenaga kerja, penentuan upah dan sistem, desain } \\
\text { keuntungan dan administrasi, kompensasi, rekrutmen, pelatihan dan } \\
\text { pengembangan, pelaksanaan, perencanaan suksesi, manajemen } \\
\text { sistem penghargaan, kebijakan pelaksanaan kesempatan kerja yang } \\
\text { sama, keamanan jabatan, serta kesejahteraan dan perbaikan pensiun. }\end{array}$ \\
\hline 1970-an:Nadler & $\begin{array}{l}\text { Pelatihan, edukasi dan pengembangan, peran karir dan ahli } \\
\text { pengembangan organisasional dengan berfokus pada keefektifan } \\
\text { produktifitas individu dan organisasi }\end{array}$ \\
\hline 1980-an & $\begin{array}{l}\text { Penciptaan kapabilitas organiasi melalui perhatian pada tekanan } \\
\text { kompetitif, penurunan biaya, perbaikan produktifitas, peningkatan } \\
\text { kulitas dan orientasi pada pelanggan }\end{array}$ \\
\hline 1990-an & $\begin{array}{l}\text { Berfokus pada sejumlah prioritas baru yang lebih berorientasi pada } \\
\text { isu-isu bisnis dan kurang berorientasi pada keahlian sumberdaya } \\
\text { manusia tradisional, diantaranya adalah mendorong tim kerja } \\
\text { antar unit fungsional, pembentukan pemikiran yang berorientasi } \\
\text { pada pelanggan, mengidentifikasi ketrampilan yang dibutuhkan } \\
\text { dan kompetensi baru, serta ekspansi global }\end{array}$ \\
\hline
\end{tabular}

Sumber: Conner dan Ulrich (1996) 
Tanggung jawab utama transformasi peran sumberdaya manusia menjadi bagian dari CEO dan setiap manajer lini. Peran sumberdaya manusia harus diintegrasikan sepenuhnya ke dalam dunia nyata perusahaan.

\section{Mengapa Persoalan SDM Sekarang Lebih Banyak?}

Saat ini persoalan sumberdaya manusia menjadi lebih banyak disebabkan oleh tantangan bisnis yang dihadapi perusahaan makin komplek, antara lain : globalisasi, peningkatan profitabilitas, perubahan teknologi yang begitu cepat, modal intelektual sebagai syarat mutlak yang harus ada pada perusahaan, berfokus pada kapabilitas, rantai nilai untuk bisnis, perubahan haluan melalui downsizing, konsolidasi, restrukturisasi, dan reengineering, serta bersifat proaktif dalam menghadapai perubahan yang terjadi disekitarnya (Ulrich, 1997).

Banyaknya tantangan bisnis yang dihadapi perusahaan membawa implikasi tersendiri bagi perusahaan. Organisasi-organisasi yang lolos dari berbagai tantangan tersebut adalah organisasi-organisasi yang memiliki tingkat kapabilitas yang tinggi. Organisasi dengan kapabilitas tinggi akan mampu dengan cepat merubah strategi ke dalam tindakan, mengelola proses secara pintar dan efisien, memaksimalkan kontribusi perbaikan dan komitmen pekerja serta menciptakan kondisi yang continuous improvement.

Guna merespon tantangan bisnis, perusahaan harus menciptakan kapabilitas organisasional baru. Ada dua kapabilitas kritis yang harus dipunyai oleh organisasi mendatang yaitu (Eichinger \& Ulrich, 1995:32):

1. Kecerdasan atau kegesitan: organisasi harus bergerak dan berubah lebih cepat, serta belajar lebih baik. Dengan kata lain organisasi harus gesit, fleksibel dan tanggap.

2. Inovasi: organisasi harus terus menerus menemukan cara-cara baru untuk berkompetisi di pasar.

\section{Peran baru Sumberdaya Manusia}

Menurut Ulrich (1997), ada empat peran baru sumberdaya manusia yaitu:

1. Mitra strategik

Para eksekuitf sumberdaya manusia harus mendorong dan memandu terjadinya diskusi serius tentang bagaimana perusahaan harus diorganisasi untuk melaksanakan strateginya. Dalam hal ini ada empat langkah yaitu : sumberdaya manusia harus bertanggung jawab untuk mendefinisikan arsitektur organisasional, malakukan audit organisasional, mengindentifikasi metode untuk merenovasi bagaimana bagian arsitektur organisasional dan mengambil inisiatif dan menyusun prioritas. Peran ini berfokus pada penggabungan strategi dan praktik-praktik sumberdaya manusia dengan strategi bisnis. Para profesional sumberdaya manusia bekerja untuk menjadi mitra strategik, membantu memastikan kesuksesan strategi bisnis. Dengan melakukan peran ini profesional-profesional sumbardaya manuisa meningkatkan kapasitas bisnis untuk melaksankan strateginya. Penerapan strategi bisnis ke dalam praktik-praktik sumberdaya manusia membantu bisnis dalam tiga 
cara yaitu : bisnis dapat beradaptasi terhadap perubahan, bisnis dapat memenuhi permintaan pelanggannya dan bisnis dapat mencapai kinerja keuangan melalui pelaksanaan strategi yang lebih efektif.

2. Ahli administratif

Sumberdaya manusia harus memperbaiki efisiensi dari fungsi tradisional mereka dan keseluruhan organisasi. Dalan hal ini membutuhkan profesionalprofesional sumberdaya manusia yang mendesain dan menghantarkan proses sumberdaya manusia yang efisien untuk staffing, rewarding, training, penilaian, promosi dan pengelolaan lain pekerja melalui organisasi secara efisien. Perbaikan efisiensi ini pada gilirannya akan membangun kredibilitas sumberdaya manusia yang pada gilirannya akan membuka pintu baginya untuk menjadi mitra strategik.

3. Pejuang pekerja (employee champion)

Sumberdaya manusia harus berbuat lebih banyak secara terus menerus yang dapat meningkatkan komitmen dan kontribusi pekerja. Pada perusahaan-perusahaan dimana modal intelektual menjadi sumberdaya kritis nilai perusahaan, profesional-profesional sumberdaya manusia akan menjadi aktif dan agresif dalam kesuksesan organisasi. Dalam hal ini profesional-profesional sumberdaya manusia harus memahami kebutuhankebutuhan pekerja dan memastikan bahwa kebutuhan-kebutuhan tersebut telah terpenuhi. Dengan cara ini diharapkan kontribusi pekerja terhadap organisasi akan meningkat.

4. Agen perubahan

Sumberdaya manusia harus membangun kapasitas organisasional untuk menangkap dan mengkapitalisasi perubahan. Inisiatif perubahan difokuskan pada penciptaan tim yang berkinerja tinggi dalam mengimplementasikan teknologi baru yang dikembangkan dan disampaikan dengan cara dan pada waktu yang tepat. Tantangan yang paling berat bagi organisasi adalah tantangan untuk merubah kultur organisasi. Guna melahirkan kultur baru, sumberdaya manusia harus melakukan empat langkah, yaitu : mendefinisikan dan menjelaskan konsep dari perubahan kultur, membuat pernyataan mengapa kultur merupakan pusat dan keberhasilan bisnis, mendefinisikan suatu proses untuk menafsirkan kultur saat ini dan kultur baru yang diinginkan serta mengukur kesenjangan diantara keduanya dan mengidentifikasi pendekatan alternatif terhadap penciptaan perubahan kultur.

Menurut Ulrich (1998), tingkat pelaksanaan keempat peran sumberdaya manusia (sebagai mitra strategik, ahli administratif, pejuang pekerja dan agen perubahan) dalam tiap organisasi berbeda-beda. Demikian juga dengan keheterogenan atau kehomogenan pelaksanaannya dan hubungan antar berbagai peran tersebut.

\section{Hipotesis 1}

Top companies di Indonesia telah melaksanakan empat peran sumberdaya manusia sebagai mitra strategik, ahli administratif ,pejuang pekerja dan agen perubahan. 


\section{Hipotesis 2}

Ada perbedaan karakter (homogen atau heterogen) dalam pelaksanaan peran sumberdaya manusia sebagi mitra strategik., ahli administratif, pejuang pekerja dan agen perubahan antar top companies di Indonesia.

Tabel 4

Kritera Sukses Bagi Empat Peran Baru Sumberdaya Manusia

\begin{tabular}{|c|c|}
\hline Peran SDM & Kriteria Sukses \\
\hline Mitra Bisnis & $\begin{array}{ll}- & \text { Kepedulian pada bottom line } \\
\text { - } & \text { Memahami pasar dan bisnis } \\
\text { - } & \text { Menjamin kesuksesan eksekusi strategi } \\
\text { - } & \text { Mempunyai visi jangka panjang tentang arah bisnis } \\
\text { - } & \text { Menterjemahkan berbagai stratregi menjadi kegiatan MSDM } \\
& \text { prioritas } \\
\text { - } & \text { Mampu untuk mendiagnosis organisasi dalam penentuan kekuatan } \\
& \text { dan kelemahan }\end{array}$ \\
\hline Ahli administratif & $\begin{array}{l}\text { - } \quad \text { Merancang dan mengembangkan proses MSDM yang efisien untuk } \\
\text { mendukung pencipataan "habitat" organisasi } \\
\text { - Menciptakan infrastruktur organisasional melalui penilaian dan } \\
\text { perbaikan proses MSDM secara konstan } \\
\text { - Melakukan kegiatan yang mengarah pada reengineering proses } \\
\text { pekaerjaan secara kontinu } \\
\text { - Menganalisis dan memberikan tanggapan terhadap kebutuhan } \\
\text { organisasioanl }\end{array}$ \\
\hline Pejuang Pekerja & $\begin{array}{ll}\text { - } & \text { Memahami berbagai SDM yang potensial mengantisipasi } \\
\text { - } & \text { kebutuhan pengembangan mereka } \\
\text { Menekankan identifikasi kompetensi yang dibutuhkan untuk } \\
\text { mengeksekusi strategi di masa mendatang, bukan hanya } \\
\text { kebutuhan sekarang } \\
\text { - } \quad \text { Mempunyai kapabilitas manajemen pendidikan dan pelatihan } \\
\text { - } \quad \text { Menganalisis berbagi cara penyediaan sumberdaya yang } \\
\text { - } \quad \text { dibutuhkan karyawan dalam memenuhi tantangan baru } \\
\quad \text { Mampu untuk mengembangkan komitmen terhadap tindakan }\end{array}$ \\
\hline Agen Perubahan & $\begin{array}{ll}\text { - } & \text { Mampu untuk mengimplementasikan perubahan strategi } \\
\text { - } & \text { Mampu untuk mengembangkan pembelajaran organisasional dan } \\
\text { - } & \text { } \quad \text { Mampu kerja serta membina hubungan } \\
\text { - } & \text { Mampu untuk menciptakan sense of urgency } \\
\text { - } & \text { Mempunyai sense of purpose malalui suatu fokus dan sistem nilai }\end{array}$ \\
\hline
\end{tabular}

Sumber:Ulrich (1997).

Profesional sumberdaya manusia seringkali disebut dengan mitra bisnis, yang kadang diartikan secara sempit sebagai profesional sumberdaya manusia yang bekerja dengan manajer-manajer umum untuk mengimplemen- 
tasikan strategi yaitu sebagai mitra strategik. Saat ini konsep mitra bisnis telah berubah tidak hanya sebagai mitra strategik saja, tetapi juga sebagai ahli administratif, pejuang karyawan dan sebagai agen perubahan. Supaya berhasil, ada beberapa kriteria yang harus dipenuhi berkenaan dengan empat peran kunci dari sumberdaya manusia ini, seperti nampak pada tabel 4.

Dalam suatu organisasi, jika satu orang menjadi arogan dan tidak respek terhadap yang lain maka semua akan menanggung dan merasakan akibatnya. Demikian juga dengan bidang sumberdaya manusia ini. Masingmasing peran ini adalah esensial terhadap seluruh peran sumberdaya manusia. Jadi keempat peran baru sumberdaya manusia tersebut merupakan suatu kesatuan. Seringkali organisasi mengutamakan peran tertentu saja dan mengabaikan peran yang lain sehingga dapat mengakibatkan tidak efektifnya fungsi sumberdaya manusia.

\section{Hipotesis 3}

Ada saling hubungan antara peran sumberdaya manusia sebagai mitra strategik, ahli administratif, pejuang pekerja dan agen perubahan pada top companies di Indonesia

\section{Kompetensi yang Diperlukan para Profesional SDM}

Supaya keempat peran baru sumberdaya manusia menjadi efektif, dibutuhkan perubahan dramatis didalam cara berpikir dan berperilaku para profesional sumberdaya manusia. Kompetensi yang harus dimiliki oleh para profesional sumberdaya manusia terdiri dari (Yeung et al., 1994: $14-15)$ :

1. Penguasaan bisnis. Persoalan sumberdaya manusia merupakan bagian penentu keberhasilan bisnis, sehingga sudah seharusnya para profesional sumberdaya manusia untuk bekerjasama dengan tim manajemen organisasi. Dengan demikian profesional sumberdaya manusia harus mempunyai pengetahuan umum di bidang keuangan, kebutuhan pelanggan eksternal, pesaing, teknologi informasi dan proses-proses bisnis lainnya.

2. Penguasaan sumberdaya manusia. Profesional-profesional sumberdaya manusia mendesain dan menghantarkan praktik-praktik sumberdaya manusia yang satu sama lain saling terkait dengan tujuan bisnis. Penting bagi para profesioanal sumberdaya manusia untuk meningkatkan perspektif sistematis dan strategik, bahkan keahlian fungsional mereka.

3. Penguasaan proses dan perubahan, artinya bahwa profesional sumberdaya manusia perlu untuk mengembangkan kompetensi dalam ketrampilan antar pribadi dan manajemen mempengaruhi untuk menangkap isu-isu secara tepat, mengidentifikasi peluang perbaikan, mendiagnosa dan memecahkan masalah, memfasilitasi pembuatan keputusan, menciptakan lingkungan yang mendukung partisipasi serta berani menghadapi resiko secara bijaksana.

4. Melakukan upgrade terhadap para profesional sumberdaya. Hal ini dilakukan kerena kemampuan mereka di bidang ini akan menentukan kualitas dan keefektifan pelayanan yang mereka berikan. Perlu bagi 
profesional sumberdaya manusia untuk mengidentifikasi secara jelas siapa pelanggan mereka.

\section{METODE PENELITIAN}

Populasi

Populasi penelitian ini adalah seluruh perusahaan yang tergolong dalam top companies di Indonesia, yang terdaftar pada Top Companies and Big Group in Indonesia edisi ke tujuh tahun 1998, yang diperkirakan telah melakukan transformasi fungsi sumberdaya manusianya.

\section{Sampel}

Responden penelitian terdiri dari para sumberdaya level menengah. Metode pengambilan sampel mengunakan metode purposive sampling, artinya seluruh top companies dikelompokkan menurut garis bisnisnya, kemudian tiap kelipatan lima perusahaan diambil sampel sebanyak satu yang dilakukan secara acak (lihat tabel 5). Semua responden terpilih diminta untuk mengisi kuesioner penelitian (satu perusahaan satu kuesioner) yang dikirimkan melalui pos. Supaya respons rate tinggi, maka dilakukan follow up.

Tabel 5

Profil Sampel Peneliltian

\begin{tabular}{|l|l|c|c|}
\hline No & Garis Bisnis & $\begin{array}{c}\text { Jumlah } \\
\text { Perusahaan }\end{array}$ & Jumlah Sampel \\
\hline 1 & Industri dan perdagangan & 152 & 31 \\
2 & Jasa & 168 & 34 \\
3 & Transportasi dan perhubungan & 62 & 13 \\
4 & Pertanian, kehutanan dan perikanan & 30 & 6 \\
5 & Bangunan dan perlengkapannya & 130 & 26 \\
6 & Kebutuhan hewan & 7 & 2 \\
7 & Bank & 141 & 29 \\
8 & Makanan dan minuman & 45 & 9 \\
9 & Peralatan kantor dan produk elektronik & 66 & 13 \\
10 & Tambang & 41 & 6 \\
11 & Peralatan dan mesin-mesin & 36 & 7 \\
12 & Bahan kimia dan obat-obatan & 74 & 15 \\
13 & Tyre & 6 & 2 \\
\hline & Jumlah & 958 & 188 \\
\hline
\end{tabular}

Metode Pengumpulan Data

Penelitian ini menggunakan data primer dan sekunder. Data penelitian tersebut dikumpulkan melalui survey dan studi pustaka. 


\section{Definisi Variabel}

1. Mitra strategik: para eksekutif sumberdaya manusia harus mendorong dan memandu terjadinya diskusi serius tentang bagaimana perusahaan harus diorganisasi untuk melaksanakan strateginya. Dalam hal ini ada empat langkah, yaitu: mendefinisikan arsitektur organisasional, mengaudit organisasi, identifikasi metode renovasi arsitektur organisasional dan mengambil inisiatif dan menyusun prioritas.

2. Ahli administratif: sumberdaya manusia harus memperbaiki efisiensi dari fungsi mereka dan keseluruhan organisasi.

3. Pejuang pekerja: sumberdaya manusia harus berbuat lebih banyak secara terus menerus yang dapat meningkatkan komitmen dan kontribusi pekerja. Dalam hal ini profesional-profesional sumberdaya manusia harus memahami kebutuhan-kebutuhan pekerja dan memastikan bahwa kebutuhan-kebutuhan tersebut telah terpenuhi, sehingga kontribusi dan komitmen pekerja terhadap organisasi meningkat.

4. Agen perubahan: sumberdaya manusia membangun kapasitas organisasional untuk menangkap dan mengkapitalisasikan perubahan. Inisiatif perubahan difokuskan pada penciptaan tim berkinerja tinggi dalam mengimplementasikan teknologi baru, yang dikembangkan dan disampaikan dengan cara waktu yang tepat.

5. Top company: perusahaan yang diakui mempunyai prestasi tertentu.

\section{Instrumen Penelitian}

Instrumen survey dalam penelitian ini berupa kuesioner yang terdiri atas 40 pertanyaan yang dikembangkan oleh Conner dan Ulrich (1996) untuk mengukur empat peran sumberdaya manusia (jadi masing-masing peran sumberdaya manusia mempunyai 10 pertanyaan). Pengukuran variabel menggunakan skala seperti Likert, dengan nilai lima angka yaitu 1 = sangat rendah (SR), 2 = rendah (R), 3 = cukup (C), 4 = tinggi (T), 5 = sangat tinggi (ST).

\section{Metode Analisis Data}

Dalam penelitian ini digunakan analisis statistik yang meliputi:

1. Mean untuk mengukur tingkat pelaksanaan masing-masing peran sumberdaya manusia pada top companies di Indonesia atau menguji hipotesis 1 . Nilai mean yang lebih tinggi menunjukkan bahwa peran sumberdaya manusia tersebut lebih dijalankan dibandingkan peran sumberdaya manusia lain. Guna menguji signifikansi perbedaan nilai mean ini digunakan analisis one-way anova.

2. Deviasi standar untuk menguji kehomogenan atau keheterogenan pelaksanaan peran sumberdaya manusia diantara top companies di Indonesia atau menguji hipotesis 2. Jika nilai deviasi standar suatu peran sumberdaya manusia adalah kecil berarti pelaksanaan peran sumberdaya manusia tersebut antar berbagai perusahaan relatif homogen (seragam atau tidak jauh berbeda) dan sebaliknya.

3. Koefisien korelasi Pearson untuk menguji hubungan antar keempat peran sumberdaya manusia pada top companies di Indonesia atau menguji 
hipoteisis 3. Nilai korelasi yang rendah atau tidak signifikan, menunjukkan keindependenan masing-masing peran sumberdaya manusia dan sebaliknya.

\section{ANALISIS DAN PEMBAHASAN}

Kuesioner penelitian yang dikirim pada 188 top companies di Indonesia, setelah dilakukan follow up (lama waktu pengumpulan data adalah Desember 1999-April 2000) memberikan total respons rate 30,85 \% atau 58 perusahaan. Apabila dikelompokkan menurut garis bisnisnya maka akan terlihat seperti pada tabel 6.

Tabel 6

Profil Responden Penelitian

\begin{tabular}{|c|l|c|}
\hline No & \multicolumn{1}{|c|}{ Garis Besar } & Jumlah Responen \\
\hline 1 & Industri dan perdagangan & 15 \\
2 & Jasa & 9 \\
3 & Transportasi dan perhubungan & 5 \\
4 & Pertanian, kehutanan dan perikanan & 0 \\
5 & Bangunan dan perlengkapannya & 8 \\
6 & Kebutuhan hewan & 1 \\
7 & Bank & 4 \\
8 & Makanan dan mimuman & 2 \\
9 & Peralatan kantor dan produk elektronik & 6 \\
10 & Tambang & 2 \\
11 & Peralatan dan mesin-mesin berat & 3 \\
12 & Bahan kimia dan obat-obatan & 3 \\
13 & Tyre & 0 \\
\hline \multicolumn{2}{|c|}{ Jumlah } \\
\hline
\end{tabular}

\section{Pengujian Hipotesis}

Untuk menguji tiga hipotesis dalam penelitian ini, ada empat analisis statistik yang digunakan yaitu:

\section{Analisis Nilai Mean dan One-Way Anova}

Mean digunakan untuk mengukur tingkat pelaksanaan masingmasing peran sumberdaya manusia sebagai mitra strategik, ahli administratif, pejuang pekerja, dan agen perubahan pada top companies di Indonesia atau menguji hipotesis-1. Suatu peran sumberdaya manusia dengan nilai mean yang lebih tinggi menunjukkan bahwa, peran sumberdaya manusia tersebut lebih dijalankan dibandingkan peran sumberdaya manusia lain yang nilai mean-nya lebih kecil. Nilai mean untuk masing-masing peran sumberdaya manusia disajikan pada tabel 7 .

Pada tabel 7 nampak nilai mean untuk masing-masing peran bervariasi mulai dari 35,05 sampai dengan 37,07 . Berdasar nilai mean, peringkat tertinggi 
pelaksanaan fungsi manajemen sumberdaya manusia adalah peran mitra strategik, kemudian diikuti oleh peran agen perubahan, ahli administratif , dan terakhir peran pejuang pekerja. Hal ini menunjukkan bahwa, pada dasarnya top companies di Indonesia telah melaksanakan empat peran sumberdaya manusia meski pada tingkat yang berbeda, yaitu peran mitra strategik lebih dilaksanakan dibanding dengan peran agen perubahan, ahli administratif, and peran pejuang pekerja.

Tabel-7

Nilai Mean untuk Masing-Masing Peran Sumberdaya Manusia

\begin{tabular}{|l|c|}
\hline Peran Sumberdya Manusia & Mean \\
\hline Mitra strategik & 37,07 \\
Ahli administratif & 36,40 \\
Pejuang pekerja & 35,03 \\
Agen Perubahan & 36,52 \\
\hline
\end{tabular}

Permasalahannya sekarang, rentang nilai mean peran sumberdaya yang relatif kecil $(2,01)$ tersebut apakah cukup signifikan? Hal ini dapat dijelaskan dengan hasil analisis one-way anova, yang mengasumsikan bahwa (a) distribusi masing-masing populasi adalah normal (b) variasi masing-masing populasi adalah sama (c) percobaan-percobaannya masing-masing independen.

Berdasar data penelitian diperoleh nilai mean, deviasi standar dan nilai $z$ untuk masing-masing peran sumberdaya manusia seperti pada tabel 8. Dengan demikian asumsi pertama dari analisis one-way anova terpenuhi.

Tabel 8

Hasil Uji Normalitas

\begin{tabular}{|c|c|c|c|c|c|c|c|c|c|}
\hline Peran & $\mu$ & sd & $\begin{array}{c}\text { Nilai z } \\
\mu-- \text { sd }\end{array}$ & $\begin{array}{c}\text { Luas (\%) } \\
\mu \pm \text { sad }\end{array}$ & $\begin{array}{c}\text { Nilai z } \\
\mu--2 \text { sd }\end{array}$ & $\begin{array}{c}\text { Luas (\%) } \\
\mu- \pm 2 \text { sd }\end{array}$ & $\begin{array}{c}\text { Nila z } \\
\mu--3 s d\end{array}$ & $\begin{array}{c}\text { Luas (\%) } \\
\mu \pm 3 s d\end{array}$ & Kriteria \\
\hline $\mathrm{Sp}$ & 37,07 & 6,71 & 1 & 68,26 & 2 & 95,44 & 3 & 99,74 & Normal \\
\hline $\mathrm{Ae}$ & 36,40 & 5,28 & 1 & 68,26 & 2 & 95,44 & 3 & 99,74 & Normal \\
\hline $\mathrm{EC}$ & 35,03 & 5,79 & 1 & 68,26 & 2 & 95,44 & 3 & 99,74 & Normal \\
\hline $\mathrm{Ca}$ & 36,52 & 6,72 & 1 & 68,26 & 2 & 95,44 & 3 & 99,74 & Normal \\
\hline
\end{tabular}

Dari nilai homogenitas varians diperoleh nilai levene statistic sebesar 1,451. Nilai ini tidak signifikan sekalipun pada $\alpha=10 \%$ (lihat tabel 9). Dengan demikian dapat dikatakan bahwa masing-masing peran mempunyai varians yang sama, yang berarti asumsi kedua dari analisis one-way anova terpenuhi. 
Tabel 9

Hasil Uji Honogenitas Varians

\begin{tabular}{|l|c|c|c|c|}
\hline & Levene Statistic & Df 1 & df 2 & Sign \\
\hline Nilai peran & 1,451 & 3 & 228 & 0,229 \\
\hline
\end{tabular}

Masing-masing peran sumberdaya manusia mengukur sesuatu yang berbeda, sehingga dapat dikatakan bahwa masing-masing peran sumberdaya manusia adalah independen (sekalipun pelaksanaan peran yang satu akan mendukung pelaksanaan peran yang lain). Hal ini berarti asumsi ketiga dari analisis one-way anova terpenuhi. Dengan demikian selanjutnya dapat dilakukan uji one-way anova.

Analisis one way anova (lihat tabel 10) menunjukkan hasil tidak signifikan. Hal ini berarti mean dari masing-masing peran sumberdaya manusia tidak berbeda secara signifikan. Artinya, keempat peran sumberdaya manusia telah dipraktikan oleh top companies di Indonesia secara seimbang

Tabel 10 Analisis One-Way Anova

\begin{tabular}{|c|l|c|r|c|c|c|}
\hline \multicolumn{2}{|c|}{} & Sum of square & \multicolumn{1}{c|}{ Df } & Mean of square & F & Sig \\
\hline \multirow{3}{*}{$\begin{array}{c}\text { Peran } \\
\text { SDM }\end{array}$} & Between group & 129,987 & 3 & 43,326 & 1,143 & 0,332 \\
\cline { 2 - 8 } & Within group & 8640,017 & 228 & 37,895 & & \\
\cline { 2 - 8 } & Total & 8769,996 & 231 & & & \\
\hline
\end{tabular}

Kesimpulan dari hasil analisis mean dan one-way anova secara umum mendukung hipotesis pertama penelitian ini, yang menyatakan bahwa, top companies di Indonesia telah melaksanakan keempat peran sumberdaya manusia.

\section{Analisis Nilai Deviasi Standar}

Deviasi standar menguji kehomogenan atau keheterogenan pelaksanaan peran sumberdaya manusia sebagai mitra strategik, ahli administratif, pejuang pekerja dan agen perubahan antar top company di Indonesia atau menguji hipotesis 2. Pelaksanaan peran sumberdaya manusia antar top company di Indonesia dikatakan relatif homogen jika nilai deviasi standarnya relatif kecil, dan sebaliknya dikatakan relatif heterogen jika nilai deviasi standarnya relatif besar.

Tabel 11 menunjukkan bahwa pelaksanaan peran ahli administratif dan peran pejuang pekerja antar top company di Indonesia relatif homogen (masing-masing nilai deviasi standarnya seniali 5,28 dan 5,79). Sementara pelaksanaan peran mitra strategik dan peran agen perubahan antar top company di Indonesia relatif heterogen (masing-masing dengan nilai 6,71 dan 6,72 ). Dengan demikian hasil penelitian ini cukup mendukung hipotesis kedua penelitian ini, yang menyatakan bahwa, ada perbedaan karakter (homogen atau heterogen) dalam pelaksanaan peran sumberdaya manusia sebagai mitra 
strategik, ahli administratif, pejuang pekerja dan agen perubahan antar top company di Indonesia.

Tabel 11

Nilai Deviasi Standar Masing-Masing Peran Sumberdaya Manusia

\begin{tabular}{|l|c|}
\hline \multicolumn{1}{|c|}{ Peran Sumberdaya Manusia } & Standar Deviasi \\
\hline Mitra strategik & 6,71 \\
Ahli administratif & 5,28 \\
Pejuang pekerja & 5,79 \\
Agen perubahan & 6,72 \\
\hline
\end{tabular}

\section{Analisis Koefisien Korelasi pearson}

Koefisien korelasi Pearson menguji hubungan antara peran mitra strategik, ahli administratif, pejuang pekerja, adan agen perubahan pada top companies di Indonesia atau menguji hipotesis 3. Nilai koefisien korelasi yang rendah atau tidak signifikan menunjukkan tidak ada saling keterikatan antar keempat peran sumberdaya manusia, dan sebaliknya.

Tabel 12 menunjukkan bahwa, ada saling hubungan secara signifikan (nilainya bervariasi antara 0,624 saampai dengan 0,774 ) antar berbagai peran sumberdaya manusia. Dengan kata lain, peran sumberdaya manusia yang satu dengan yang lain saling mendukung, meski masing-masing peran adalah independen (sesuatu yang berbeda satu sama lain). Hasil ini mendukung hipotesis ke tiga penelitian, yang menyatakan, ada saling hubungan antara peran mitra strategik, ahli administratif, pejuang pekerja dan agen perubahan pada top companies di Indonesia.

Tabel 12

Koefisien Korelasi Pearson antar Berbagai Peran Sumberdaya Manusia

\begin{tabular}{|l|c|c|c|c|}
\hline & $\begin{array}{c}\text { Mitra } \\
\text { Strategik }\end{array}$ & $\begin{array}{c}\text { Ahli } \\
\text { Administratif }\end{array}$ & $\begin{array}{c}\text { Pejuang } \\
\text { Pekerja }\end{array}$ & $\begin{array}{c}\text { Agen } \\
\text { Perubahan }\end{array}$ \\
\hline Mitra Strategik & & & & \\
\hline Ahli Administratif & $0,774 * *$ & & & \\
\hline Pejuang Pekerja & $0,624 * *$ & $0,740 * *$ & & \\
\hline Agen Perubahan & $0,769 * *$ & $0,708 * *$ & $0,720 * *$ & \\
\hline
\end{tabular}

$\left.{ }^{* *}\right) p<0,01$ 


\section{Pembahasan}

Berdasarkan pengujian hipotesis yang telah dikemukakan sebelumnya, maka hasilnya dapat diringkas seperti nampak pada tabel-13.

Tabel 13

Ringkasan Hasil Pengujian Hipotesis

\begin{tabular}{|c|c|c|c|c|c|c|}
\hline \multirow[b]{2}{*}{ Analisis } & \multicolumn{4}{|c|}{ Peran sumber daya manusia } & \multirow[b]{2}{*}{ Hipotesis } & \multirow[b]{2}{*}{ Keterangan } \\
\hline & $\begin{array}{c}\text { Mitra } \\
\text { Strategik }\end{array}$ & $\begin{array}{c}\text { Ahli } \\
\text { Administratif }\end{array}$ & $\begin{array}{l}\text { Pejuang } \\
\text { pekerja }\end{array}$ & $\begin{array}{c}\text { Agen } \\
\text { Perubahan }\end{array}$ & & \\
\hline \multirow[t]{2}{*}{ Mean } & 37,07 & 36,40 & 35,03 & 36,52 & \multirow[t]{2}{*}{1} & \multirow[t]{2}{*}{ Didukung } \\
\hline & Anova $F=$ & 143 dengan S & 0,332 & & & \\
\hline $\begin{array}{l}\text { Deviasi } \\
\text { standar }\end{array}$ & 6,71 & 5,28 & 5,79 & 6,72 & 2 & Didukung \\
\hline Korelasi & 1 & 0774 & 0624 & 0769 & 3 & \\
\hline- aa & 0,774 & 1 & 0,742 & 0,708 & & \\
\hline$-\mathrm{pp}$ & 0,624 & 0,742 & 1 & 0,720 & & \\
\hline - ap & 0,769 & 0,708 & 0,720 & 1 & & \\
\hline
\end{tabular}

Berdasarkan nilai mean dan analisis one-way anova (tabel-7 dan tabel -10) mengindikasikan bahwa keempat peran sumberdaya manusia telah dipraktikkan oleh top companies di Indonesia secara seimbang. Hasil penelitian ini berbeda dengan hasil penelitian Conner dan Ulrich (1996) yang menunjukkan bahwa, peran pejuang pekerja dan ahli administratif lebih dijalankan dibanding peran mitra strategik dan agen perubahan.

Telah dipraktikkannya keempat peran sumberdaya manusia secara seimbang oleh top companies di Indonesia adalah dimungkinkan, mengingat data primer yang dipakai dalam penelitian ini dikumpulkan pada periode Desember 1999-April 2000 (dua tahun lebih saat krisis ekonomi mulai melanda dunia, yaitu di awal tahun 1997). Pada periode tersebut top companies di Indonesia telah menyadari bahwa lingkungan bisnis telah banyak berubah. Konsekuensinya, manajemen perusahaan harus dibenahi agar tetap bisa survive. Menurut Ulrich (1987), kebutuhan pengembangan kapabilitas organisasi mengarah pada peran baru fungsi sumberdaya manusia. Dengan demikian fungsi sumberdaya tidak hanya berperan sebagai ahli administratif saja (peran tradisional) tetapi juga berperan sebagai mitra strategik, pejuang pekerja dan agen perubahan. Keempat peran fungsi sumberdaya manusia ini harus dijalankan secara seimbang satu sama lain.

Selain itu, Wright dan koleganya (dalam Youndt et al., 1996) menemukan bahwa, organisasi mempunyai kinerja yang tinggi ketika mereka menggunakan para pekerja dengan kompetensi yang konsisten terhadap strategi perusahaan, dan juga konsisten dengan lingkungan eksternal perusahaan.

Hasil analisis nilai deviasi standar (tabel-11) menunjukkan bahwa, pelaksanaan peran ahli admisnistratif dan peran pejuang pekerja antar top 
company di Indonesia relatif homogen (masing-masing nilai deviasi standarnya senilai 5,28 dan 5,79), sementara pelaksanaan peran mitra strategik and peran agen perubahan antar top company di Indonesia relatif heterogen (masingmasing dengan nilai 6,71 dan 6,72). Hasil penelitian ini sejalan dengan hasil penelitian Corner dan Ulrich (1996) yang juga menunjukkan pelaksanaan peran pejuang pekerja dan ahli administratif bersifat homogen antar berbagai perusahaan, sementara pelaksanaan peran mitra strategik dan agen perubahan bersifat heterogen atau berbeda-beda antar top company di Indonesia.

Dengan tidak berfungsinya secara optimal serikat pekerja atau buruh yang ada di Indonesia mengakibatkan posisi buruh ada di pihak yang lemah. Mereka selalu kalah dalam menentukan bergaining dengan para pengusaha yang memiliki modal. Akibatnya, keberadaan para buruh tersebut hanya dipandang sebelah mata, hanya sebagai obyek dan bukan sebagai subyek, sehingga harga merekapun murah. Hal ini ditunjukkan dengan kecilnya upah yang mereka terima. Dalam kondisi seperti ini pemerintah merasa perlu untuk membuat kebijakan dalam penetapan upah minimum regional (UMR). Akibatnya, pelaksanaan peran ahli administratif dan peran pejuang pekerja antar top company di Indonesia menjadi relatif homogen. Sebaliknya, pelaksanaan peran mitra strategik dan agen perubahan lebih bersifat heterogen atau berbeda-beda antar top company di Indonesia. Hal ini dikarenakan top companies di Indonesia bergerak dalam garis bisnis yang berbeda, selain masing-masing perusahaan mempunyai budaya, visi dan misi, tujuan serta strategi yang berbeda pula. Dengan demikian sangatlah wajar jika kemudian terdapat variasi dalam pelaksanaan peran mitra strategik dan agen perubahan.

Berdasar hasil analisis matrik korelasi (tabel-12) nampak bahwa, ada saling hubungan yang cukup berarti (nilainya bervariasi antara 0,624 sampai dengan 0,774 ) antar berbagai peran sumberdaya manusia. Dengan kata lain peran sumberdaya yang satu dengan yang lain saling mendukung, meski masing-masing peran adalah independen (sesuatu yang berbeda satu sama lain). Hasil penelitian ini berlawanan dengan hasil penelitian Conner dan Ulrich (1996), yang menunjukkan adanya hubungan yang rendah antar berbagai peran kecuali antara peran mitra strategik dan agen perubahan.

Disadari bahwa, jika satu orang telah menjadi arogan dan tidak respek terhadap yang lain, bisa dipastikan kinerja yang dihasilkan tidak akan baik. Demikian pula dengan empat peran sumberdaya manusia ini. Sekalipun masing-masing peran adalah sesuatu yang berbeda satu sama lain, namun diakui bahwa masing-masing peran ini esensial terhadap seluruh peran sumberdaya manusia. Jadi keempat peran sumberdaya manusia tersebut saling mendukung satu sama lain, sebagai kesatuan. Dengan demikian kinerja yang dihasilkan diharapkan jauh lebih baik. 


\section{PENUTUP}

\section{Simpulan}

Berdasar permasalahan, tujuan dan hasil penelitian ini, secara umum dapat diambil beberapa simpulan sebagai berikut:

1. Pada umumnya top companies di Indonesia telah melaksanakan empat peran sumberdaya manusia secara seimbang. Hal ini diperlukan untuk pengembangan kapabilitas organisasi dalam menghadapi tantangan bisnis yang makin komplek.

2. Pelaksanaan peran ahli administratif dan peran pejuang pekerja antar top company di Indonesia relatif homogen sementara pelaksanaan peran mitra strategik dan peran agen perubahan antar top company di Indonesia relatif heterogen.

3. Masing-masing peran sumberdaya manusia saling mendukung satu sama lain meski masing-masing peran merupakan sesuatu yang berbeda satu sama lain.

\section{Keterbatasan}

Penelitian ini mempunyai sejumlah keterbatasan yang mungkin dapat mempengaruhi hasil penelitian. Beberapa keterbatasan tersebut diantaranya adalah :

1. Penelitian ini hanya dapat dilakukan pada perusahaan-perusahaan yang telah melakukan transformasi di bidang sumberdaya manusia. Jika penelitian ini dilakukan pada perusahaan yang belum melakukan transformasi di bidang sumberdaya manusia dimungkinkan akan ditemukan bahwa peran-peran baru sumberdaya manusia tersebut tidak dipraktikkan.

2. Meski peneliti telah berusaha untuk mengambil sampel secara merata pada seluruh garis bisnis top companies agar terwakili, namun karena tingat response rate ada di luar jangkauan peneliti maka dimungkinkan responden yang terpilih terkonsentrasi hanya pada beberapa garis bisnis saja, sementara garis bisnis yang lain tidak terwakili. Hal ini tentunya akan mengurangi kemampuan generalisasi hasil penelitian.

3. Pada penelitian ini tidak tertutup kemungkinan bias respon, terutama berkaitan dengan penggunaan persepsi manajer sumeberdaya manusia tingkat menengah dalam menjawab pertanyaan-pertanyaan kuisioner, sehingga ada faktor subyektifitas yang relatif tinggi. Pengukuran self rating scale semacam ini kemungkinan dapat menyebabkan adanya kecenderungan para responden mengukur lebih tinggi dari kondisi sesungguhnya. Kecenderungan tersebut menurut John (1996) merupakan rater errors yang disebut sebagai efek liniency.

Implikasi

Terlepas dari keterbatasan yang dimiliki, diharapkan hasil penelitian ini dapat memberikan dua segi implikasi. Implikasi yang pertama sifatnya berupa praktik atau implikasi manajerial bagi perusahaan dalam menggali dan 
mengidentifikasi peran-peran yang harus dimainkan dan dikembangkan oleh departemen sumberdaya manusia dalam persaingan dunia bisnis yang semakin ketat. Pelaksanaan peran sumberdaya manusia ini penting untuk dikomunikasikan dan dikembangkan secara terus menerus guna meningkatkan ketrampilan, pengetahuan dan kemampuan mereka. Selanjutnya, mereka dapat mengintegrasikan peran sumberdaya manusia kedalam kerangka kerja dan alat-alat diagnostik yang digunakan dalam perencanaan karir, suksesi, seleksi dan pengembangan sumberdaya manusia, serta ke dalam seluruh sistem organisasi.

Implikasi yang kedua berupa implikasi teoritik dan metodologik bagi para akademis dan peneliti lainnya, dalam rangka mengembangkan segi teoritis yang berkaitan dengan manajemen sumberdaya manusia yang akan terus berkembang. Dengan demikian hasil ini minimal dapat menambah referensi dan mendorong dilakukannya penelitian-penelitian peran fungsi sumberdaya.

Peran-peran baru sumberdaya manusia akan terus berkembang atau berubah secara dinamis sejalan dengan perubahan lingkungan dan perkembangan dunia bisnis itu sendiri. Dengan demikian peneliti yang hendak meneliti peran sumberdaya manusia di masa yang akan datang, perlu kiranya untuk meninjau dan mengevaluasi kembali perkembangan peran-peran baru sumberdaya manusia dan instrumen pengukurannya secara terus menerus. Konsekuensinya, perlu juga dilakukan identifikasi kapabilitas baru yang harus dipunyai oleh sumberdaya manusia untuk meraih keunggulan kompetitif di masa mendatang.

\section{DAFTAR PUSTAKA}

Becker, B and Gerhart, B. 1996. The Impact Resource Management on Organizational Performance : Progress and Prospect. Academy of Management Journal, 39 (4) : 779-801.

Conner, J. and Ulrich, D. 1996. Human Resource Roles : Creating Value, Not Rhetoric. Human Resource Planning, 19 (3) : 38-49.

Conner, J. and Jeana, W. 1993. Managing the Transformation of Human Resource Work. Human Resource Planning, 16 (2) : 17-34.

Cooper, R.D. and Emory W.C. 1995. Business Research Methods (5th ed.). London : Richard D. Irwin, Inc.

Eichinger, B. and Ulrich, D. 1995. Are You Future Agile. Human Resource Planning, 18 (4) : 30-41.

Ferris, R. G. 1994. Handbook of Human resource Management. Oxford : Blackwell Publishers.

French, L. W. 1986. Human Resource Management. Boston : Houghton Mifflin Company.

Fryzell G.E and Wang J. 1994 The Fourtune Corporation Reputation Index : Reputation for What ? Journal of Management, 20 : 1-14. 
Higgins, A. C. 1990. Champions of Change : Identifying, Understanding and supporting Champions of Technological Innovations. Organizational Dynamics, Summer 19 (1) : 40.

Huselid, A. M and Jackson, E.S and Schuler S.R 1997. Technical and Strategic Human Resource Champions of Effectiveness As determinants of Firm Performance. Academy of Management Journal, 40(1) : 171-188.

Ichiniowski, C. , Shaw, K. , and Prennushiu, G. 1994. The Effect of Human Resource Management Practices on Productivity. Working Paper, Columbia University, New York.

John, G. 1996. Organizational Behavior : Understanding Life at Work (4th ed.). New York : Harper Collins, College Publisher.

Lado, A. A. and Wilson, C. M. 1994. Human Resource System and Susteined Competitive Advantage : A Competency-Based Perspective. Academy of management Review, 19 (4) : 699-727.

Mendenhall, W. and Beaver J.R. 1992. Acourse in Business Statistics (3th ed.). Boston: PWS - Kets Publishing Company.

Miles, R.E. and Snow, C. C. 1984. Designing Strategic Human Resource Systems. Organizational Dynamics, $13: 36-52$.

Pigors, P. and Myers, A. C. and Malm, T.f. 1973. Management of Human Resource : Reading in Personnel Administration. New York : McGraw-Hill Book Company.

Schermerhorn, R.J. 1996. Management (5 $5^{\text {th }}$ ed.) New York : John Wiley \&sons, Inc.

Schuler, S.R and Jackson, E. S. 1987. Linking Competitive Strategies with Human Resource Management Practices. The Academy of Management Executive, 1(3) : 207-219.

Schuler, S. R. 1990. Reposition The Human Resource Function : Transformation or Demise ? Academy of Management Executive, 4 (3) : 49-60.

Schuler, S. R. 1992. Strategic Human Resource Management : Linking the People with the Strategic Needs of The Business. Organizational Dynamics, Summer, 21(1) : 18.

Schuler, S.R and Walker, W. J. 1990. Human Resource Strategy : Focusing on Issue and Actions, Organizational Dynamics, Summer.

Ulrich, D. 1997. Human Resource Champions : The Next Agenda for Adding Value and delivering Result. Boston: Harvard Business School Press.

Ulrich, D. 1998. A. New Mandate for Human Resources. Harvard Resource Planning, January-February.

Walker, W.J. 1991. Managing Human Resource in That, Lean and Flexible Organization : Trend for the 1990's. Human Resource Planning, 11(2).

Wiley, C.B. 1992. A Comprehensive View of Roles for Human Resource Managers in Industry Today. Industrial Management, p. 27-29.

Yeung, A., Brockbank, W. and Ulrich, D. 1994. Lower Cost, Higher Value : Human Resource Function in Transformation. Human Resource Planning, 17(3) : 1-16. 
Yeung, A. and Ulrich, D. 1989. A. Shared Mindset. Personnel Administrator, P. $38-45$.

Youndt, A.M., Snell, A. S. and Dean, W. J. and Lepak, P.D 1996. Human Resource Management, manufacturing Strategy and Firm Performance. Academy of Management Journal, 39 (4) : 836-866. 